\title{
A global space policy that would revive space exploration
}

\author{
Tanay Sharma*, Prof. C.R.C Chatwin, Dr. R.C.D Young, Dr. P. Birch \\ School of Engineering \\ University of Sussex \\ Brighton, United Kingdom \\ t.sharma@sussex.ac.uk
}

\begin{abstract}
Almost every nation today relies on space-based technology for communications, weather forecasting, satellite navigation and resource management, either through indigenous programs or through programs run by its allies. As such, it is safe to say that every country is a space-faring nation. However, when it comes to space science and technology, attention must be directed towards countries that possess the ability to launch payloads.
\end{abstract}

Russia, Japan, China, ESA, India, Israel, Iran and the United States form an exclusive club of nations that not only possess launch capability but also dominate research and development in space sciences. With the exception of the ESA, whose space policy is dictated by its member states and primarily serves the $\mathrm{EU}$, all other countries have national space programs governed by a dedicated space policy. However, all states including the EU have the following objectives in common:

1. Development and exploitation of space applications to serve the state's public policy objectives,

2. Ensuring that the state's national security and defense needs are met with regards to space,

3. Securing unrestricted access to critical technologies allowing states to pursue independent applications, and

4. To further international collaboration between likeminded nations through improved coordination of international activities and by setting in place a better mechanism for sharing of resources.

Whilst the above nations agree in principal to the UN Outer Space Treaty, and they all consider space as a vital resource for ensuring national security. As such, any application or development of critical technologies is used primarily to bolster a state's national defense capability. Current national space programs run by these countries cover various commercial, civilian and military aspects. This cross discipline research and development has led to an extremely integrated industrial base, where drawing a line between civilian and military programs is often impossible. This hazy line has often hindered technology transfer even in commercial applications as companies grapple with stringent export control regulations. With respect to the United States, whilst ITAR has ensured that critical technology is not transferred without the states consent, many in Washington agree that the regulation fails to meet its objectives and must be overhauled. It has also hindered US companies wanting to sell their products outside the United States, prompting other nations to develop indigenous technologies and market them as ITARfree.

Although it is safe to assume that research and development with regards to space will be dominated by the United States and its partners in Europe for the foreseeable future, the recent recession has caused financial strains on both sides of the Atlantic causing drastic changes with regards to space budgets and the future outlook for both NASA and ESA.

This paper briefly discusses why emerging nations might consider investing in a national space program, and factors that would determine its success. It also focuses on how the establishment of a global space program could prove to be an innovative and cost-effective way of ensuring a robust space industry that serves the social and political objectives of member nations whilst promoting a global technological base that fosters innovation, growth and sustainable development.

Keywords- space program, export control, munitions list, industrial base, ITAR

\section{INTRODUCTION}

It is safe to assume that every nation today has a potential stake or is in some way involved in space based activities. For a number of nations space is a vital resource for ensuring national security. As such, developments and applications of critical technologies with regards to space are often primarily used to bolster a state's national defense capability. Whilst this may not be the primary objective for all nations, the ever growing focus on national defense and security has divided the space industry into civil, commercial, military and intelligence industries, with an extremely hazy distinction between the various sections. Space is probably one of the few industries where almost every component or technology developed could be potentially classified as dual-use. It is this distinction that has often hindered nations from transferring technology, skills and developing international cooperation. However, the limitations of trade and transfer of technology has created new space-faring nations who have replicated the restricted technologies, where their focus now lies on developing indigenous technology and competing in the international market. 
The following sections of this paper will consider why nations might choose to initiate a national space program, the role of the United States and the impact of ITAR, and how establishing a global space program with a common defined policy could prove to be an innovative and cost-effective way of cultivating a robust space industry that serves the social and political objectives of member nations whilst promoting a global technological base which fosters innovation, growth and sustainable development.

\section{THE ELEMENTS REQUIRED FOR THE INITIATION OF A SUSTAINABLE NATIONAL SPACE PROGRAM}

Today whilst most countries are involved in space activities only nine can be considered to be space faring nations, i.e. they possess the technological capability for launching payload. If we trace the origins of national space programs (NSP) in these nine nations we find that they were all initiated due to a successful combination of the following elements:

- Power: or the perception of power is vital for all nations. By developing a NSP, the nation becomes a member of an exclusive club. This membership often comes with fringe benefits like technology transfer, training and development of inter-agency cooperation.

- Pride: NSP's are often used by nations to demonstrate their technological might to the rest of the world. In effect they often become a symbol of national pride.

- Politics: Both local and national politics play a crucial role in the development of any space program. Let's take the United States as an example: The US space program, initiated at the height of the Cold war was more of a political decision than anything else. It was a political standoff that prompted the US to enter the space race, it was a political decision to put a man on the moon and it is both local and national politics that ensures that NASA still exists.

- Technology: A NSP ensures that there is R\&D of the highest standards within the nation. This cutting edge $\mathrm{R} \& \mathrm{D}$ is not only applied to bolster a nations national defense systems but often finds use in various civilian applications. Almost all of the technology developed as part of a space program finds primary use in national defense and military applications.

- Economics: NSP's and R\&D related to space science $\&$ technology is definitely not cheap. Its cost can most definitely put a strain on national finances, especially when pursued by developing nations. Current funding for NSP's runs into billions of dollars; however nations determined to initiate a NSP have to overcome the significant economic hurdle. We should also remember that nations wishing to assert themselves as space faring, often do so because of nationalistic pride and as such are ready to bear the costs involved despite the financial burden. E.g. in 2003 Nigeria funded its first satellite NigeriaSat-1. Whilst this was a great feat for Nigeria, it was extremely expensive as the microsatellite cost approximately $\$ 13$ million. A significant sum for a country whose annual budget was just over $\$ 3$ billion and with $\$ 30$ billion in foreign debt.

The above drivers are combined together as below to represent a NSP:

$$
\sum(P) \times T \times E=N S P
$$

Where $\sum(P)$ represents a combination of power, pride and politics; $T$ is technology and $E$ is economics. Once initiated, all NSP's require the following variables to be met consistently in order to ensure the sustainability and further development of the NSP.

- Politics (P): Both developing and developed nations need to be able to justify the need for a NSP. They require majority support for any chance of success both at state and national levels. Furthermore, there needs to be legislation in place that protects the interests of all parties involved with the NSP whilst ensuring that the program yields national benefits, and ensures that the nation's defense and national security needs are met

- Economics (E): Nations not only require ready capital for the initiation of the NSP, but must also ensure that there is a budget allocation associated with the NSP. The objectives of the NSP must be clearly defined and sources of revenue and income generation should be identified prior to its establishment. The action-plan generated for a NSP must have provisions that ensure that there exists a viable economic return.

- Technology (T): Nations keen on initiating and developing a NSP must ensure that they possess a strong research base, and have links to relevant industry. Nations should be able to develop indigenous technologies whilst ensuring an ample supply of locally sourced skilled labor. Whilst technical collaboration between nations \& research groups is essential, there must be checks in place that ensure critical technologies are not transferred or sold without a MOU with other likeminded nations. As such, nations should also make certain that embargos on technology transfer imposed by others do not limit national capability with regards to space.

If any of the above requirements are not satisfied, sustaining the development of a NSP becomes increasingly difficult. It should be noted that currently all NSP's are funded by a national budget and serve the commercial and strategic interests of their respective nations as laid down by their governing space policy. The only exception to this is the ESA, which is governed by a space policy laid out by the EU and its member nations. The ESA budget is controlled by the EU, which is in turn allocated funds from the national budgets of member states. 


\section{IMPACT OF EXPORT CONTROL ON THE U.S INDUSTRIAL} BASE

Space is now truly a global industry. Companies and enterprises, within established political limits, compete to provide launch and industry services internationally. Satellite development, was once primarily dominated by US companies, it is now conducted internationally by companies located across the globe [1]. However, the US space industry is currently concerned that its competitiveness is being undermined by the export control regime that regulates trade between the US and the rest of the World [2]. A survey conducted by the Space Foundation in 2007, shows that while US companies are aware of the need to protect certain critical technologies, they do not believe that regulations like ITAR are working the way they should. The survey also indicates that smaller companies are most likely to feel adverse effects from ITAR than their larger counterparts. This is alarming as lowtier contractors are a significant source of new technology and innovation within the US.

There is no doubt that ITAR is an essential tool to help protect critical technology, however there needs to be a radical change in both the regulations and processes of implementation. The focal point for change should be the modernization of ITAR to reflect the current global market, the state of space technology and the increasing pace of innovation. It should be noted that the US space industrial base is largely dependent on the US defense/national security budget. The implication is that the national security community "owns" the US space industry, and must either provide for the health of the industry or encourage and enable it to participate more in the global market to broaden its economic base [3].

One of the goals of the US National Space Policy is to "encourage international cooperation with foreign nations on space activities that are of mutual benefit"; it also states "space-related exports that are currently available or are planned to be available in the global marketplace shall be considered favorably". However, in certain instances it is evident that elements of the US export control laws are in conflict with US National Space Policy. The US space export control regime does not seem to match its goals of both enabling cooperation with allies and denial of capabilities to opponents. The current regime does not provide policy makers the nuance or flexibility needed to serve the National Space Policy. Congressional action helped place satellites and their components back on the US munitions list in 1999, with the intent of limiting the spread of space technology. However, this has had the unintended consequence of encouraging the proliferation of space capabilities and has not prevented the rise of other space powers. In turn, export control policies have restricted US engagement and partnership, whilst encouraging foreign space capabilities. To put this in perspective, since 1999 when the US was part of a very exclusive club, the number of nations active in space has continued to grow so that today:

- There is triple the number of countries with their own positioning/navigation systems.

- There is double the number of countries with their own reconnaissance/earth observation satellites.
- There are now a dozen countries capable of launching their own satellites, and

- There are 38 countries with operational control over their own communication satellites

Furthermore, this rapid growth has meant that the sophistication of overseas and commercial capabilities has steadily increased. ITAR implementation and it adverse industrial and technological impact means that US companies trying to compete in the global market lose as much as $\$ 600$ million a year, which in turn feeds space development that the US is not involved in [3]. It should be noted that at present the US has treaties with the United Kingdom and Australia that enable technology transfer of certain items without being constrained by export control regulations. However, although the treaties have been signed they are yet to be ratified by the US Senate, with various members of the administration arguing that critical US technology must remain in-house. All of this clearly indicates that the strategic intent of the space export controls is not being achieved.

Exports of space products and services in the US fall under the jurisdiction of the Department of State (DOS), regardless of their purpose, whether it is military, civilian, commercial or academic. These transactions are covered by ITAR and are considered by many members of the space industry to be a government-imposed hindrance that prevents the US from reaching its full potential as a leader in global space activity.

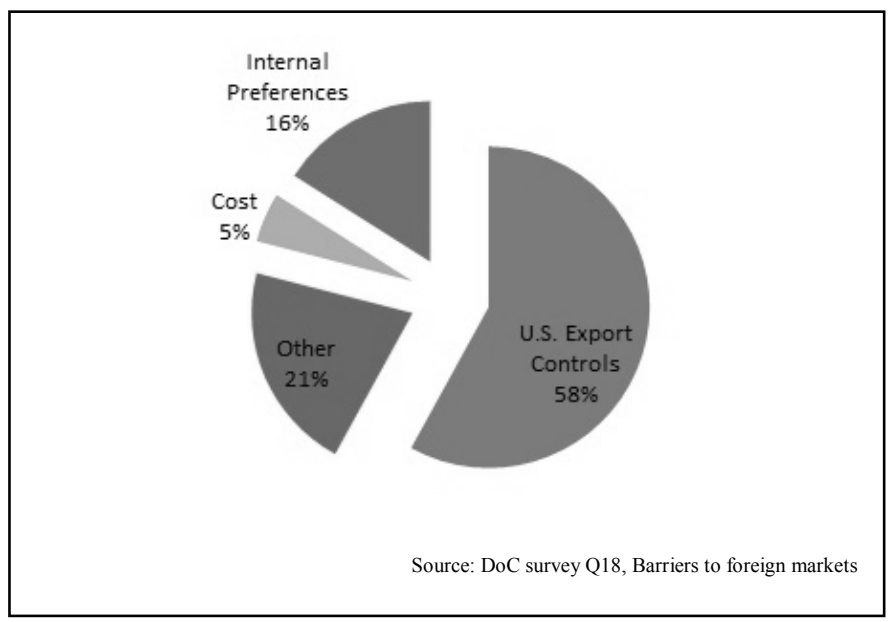

Figure 1. Export Control as barrier to foreign markets

A joint survey conducted by the U.S. Department of Commerce (DOC), Bureau of Industry and Security (BIS), Defence Science Board (DSB), National Security Space Office (NSSO), AFRL and NASA [4] in 2007 showed that 58\% of the companies questioned, listed export control as the main barrier to gaining entry when attempting to market products in foreign countries, as shown in fig 1.

Over the last decade the US congress has discussed extensively a broad range of issues affecting the competitiveness of the US aerospace manufacturing industry. In FY2010 the 'Presidential Commission on the Future of the US Aerospace Industry' released its recommendations on how to maintain the competitiveness of the aerospace sector [9]. The commission called for a national policy along with a 
government wide framework and the removal of prohibitive legal and regulatory barriers that impede the ability of the industry to grow [6], a point echoed by the Space Foundation survey in 2008 as represented in fig2.

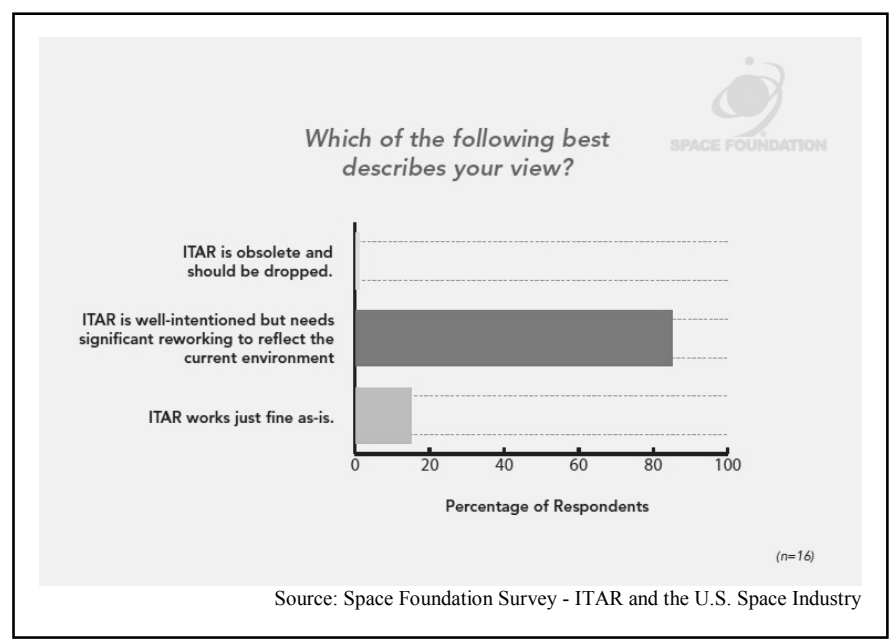

Figure 2. Industry views on ITAR

Industry analysts have long argued that globalization is the key to achieve business objectives, enhance competitiveness and vitality of exports for the US, however export licensing laws and their wording hinders progress. While Tier 1 firms have learned to manage export control requirements, they remain a burden for Tier 2 and Tier 3 companies [3]. The extra cost associated with export control compliance, not only discourages the low tiers but forces them to rely on the U.S. domestic market. Figure 3 shows the financial costs (2003-06) related to export control compliance for all tiers. Whilst Tier 1 accounts for over half the costs, Tier 2 and Tier 3 combined report significant costs of over $\$ 85 \mathrm{M}$ for a four-year period.

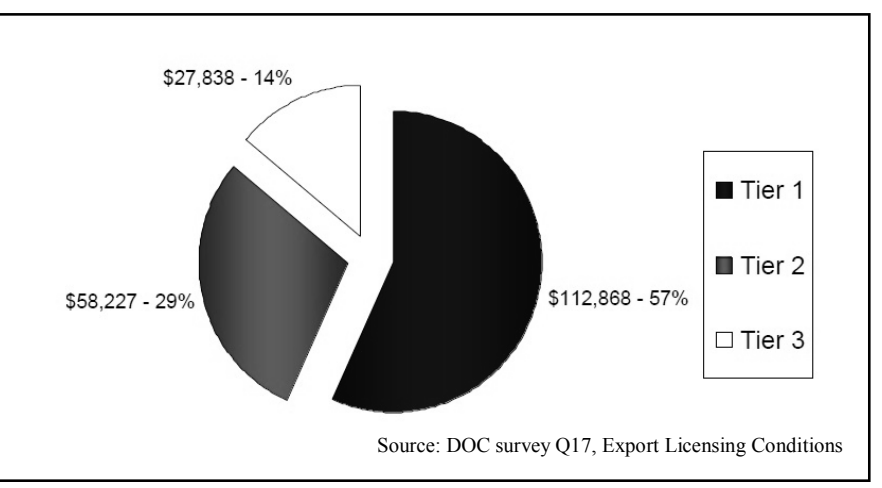

Figure 3. Financial costs of export control compliance (\$K)

If it were easier to compete globally, smaller companies would have a better chance of survival during lean times. The loss of lower tier companies will eventually lead to a decline in development of new technology within the US [7]. An indicator of this decline is the rise of companies overseas developing indigenous technologies and marketing them as ITAR-free [3]. India, China and South Korea are the most recent examples of countries that have in some way benefited due to ITAR. The technology base within these countries has grown significantly, allowing them to collaborate with other space agencies on various projects. The steady rise in the number of space participants brings with it a variety of positions regarding the future of space activity. These positions emerge from the capabilities and experience of new participants on various national projects and underline their future space investments. The rise in the number of participants, be it public or private sector entities, demands a collective reflection on new rules, guidelines and policy implementation strategy that guarantees development of space activities with the consistent notion of common good in order to gain widespread adherence ${ }^{1}[8]$.

\section{GLOBAL SPACE PROGRAM WITH A GLOBAL SPACE POLICY}

The current space industry comprises of 3 tiers of capabilities and products. The first tier includes principal companies with integrated design and production capabilities for fully integrated stand-alone systems. The second tier companies manufacture systems and major substructures like engines, fuel control systems and communication systems for the principal companies; whilst the third tier comprises of suppliers of components and parts and other specialized services. In order for the global space industry to grow, there needs to be opportunity for healthy competition [9]. This however can only be achieved if all companies involved in the space sector are allowed to compete for the same projects. However, due to the very nature of the industry there lies interdependence between the various sectors, as illustrated in fig 4.

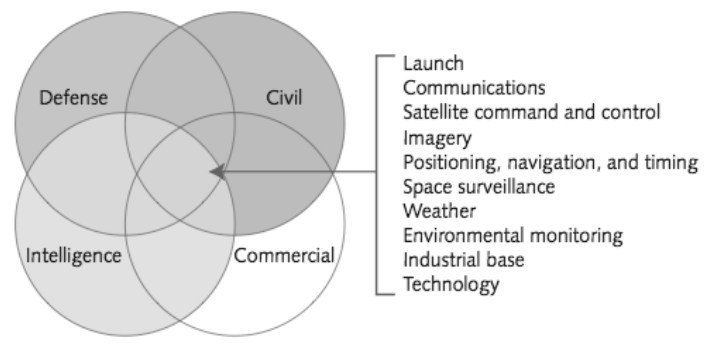

Source: CSIS Defense-Industrial Initiatives Group concept.

Figure 4. Space sector interdependence

Since it is not always possible to clearly distinguish between the civilian and military applications of space-based technology, it might be worth considering a global space program (GSP). Such a program would take into account various actors, their values and views with regards to space, and would promote global science by identifying future trends and encouraging regional co-operation. The purpose of a global space program is not to overshadow international engagement taking place through the UN or bodies like SWF, but to streamline the process by implementing a global umbrella policy that would focus all actor investments to ensure the sustainable development of space based research. By adopting

${ }^{1}$ Adapted from "A European approach to space security" by Xavier Pasco [8] 
a global space program and along with it a global policy, we could ensure that there is targeted $\mathrm{R} \& \mathrm{D}$, hence, a better return on investments made by the public/private sector, greater potential for expanding capability beyond that of a single nation program and reduce the risk associated with 'rouge actor' activities, as each member party (private or public) would have a vested interest.

Although a simple enough idea, its implementation would be rather complex. In order to start such a program, we would not only require nations to streamline their export control policies, but would also require them to define export control based on an international standard whilst finding the right balance between national interests and global prosperity. The verified end user database could be implemented on a global scale allowing nations to exchange technology, resources and offer services whilst complying with national and agreed international export control policies. Even though the wording of a governing policy for such an endeavor would be subject to intense international debate, it is possible to find a middle ground without compromising the industrial base. A GSP could also be used as a platform to develop new propulsion technology, enabling us to guarantee affordable, reliable, safe sustainable access to space. This could be achieved by the program investing in technologies like the vacuum maglev system (VML) $[10,11,12]$ that has significant environmental and economic benefits compared to conventional launch systems.

There are a number of examples that illustrate how international cooperation and private-public-partnership can and does work in delivering key results, such as the ISS, Antartic Treaty and Skynet respectively. Based on these examples, one of the main ways to achieve a GSP would be to establish a consortium of like-minded nations with verified end users who broadly agree to the following:

- To cooperate in full with regards to a global space program. Similar to the collaboration required for the International Space Station, this point suggests bringing together like-minded nations, who intend to use space as a resource to benefit all humankind. By doing so, member states encourage technology and skills transfer that helps build a competitive environment for industry, leading to accelerated R\&D. This proposal also makes it possible to develop and define a verified end user list for each participating nation, the controlling body for the end user, and the type of research or development it specializes in.

- To set up a global charter that outlines the civil space milestones to be achieved by the consortium

- By outlining key milestones and pooling together resources, member nations encourage growth of the civil space sector, ensuring that both consortium and national benchmarks are met. It also ensures that member nations agree to a stringent set of policies that will govern such a program. As it stands today, most space faring nations govern their activities through a central space policy. Almost all national space policies discuss the importance of a collaborative effort, however they do not clearly define the approach nations should take or consider existing legislation that hinders progress. To comply in full with policies and directives laid out by the consortium, and in turn inform governments of member states of progress made on projects and milestones in a timely manner. This is primarily to ensure that there exists a system of checks and balances. As member nations are effectively stakeholders in the consortium, and are liable under current international law for activities conducted on their behalf or by companies associated by origin; it is vital to ensure that there is a periodic review of activities conducted by the consortium and that all regulations are met by each member state. This process would also enable member nations to debate and discuss various aspects of the consortium, allowing them to fine tune policy, law and directives to better suit the global need.

- Enable local industry and talent to compete on a global scale, by providing financial and technical support as and when required - Currently, private firms find it extremely hard to go it alone when it comes to space. Even if firms had the necessary capital and manpower, the risk involved with space programs is high. Firms that are currently involved with space programs are contracted by national agencies, and as such their research focus is directed by the governing agency. Consortium members could provide financial incentives to the private sector to rejuvenate the industry and in turn the consortium could become the primary customer for all the technologies developed. By doing so the consortium not only reduces the risk factor for private firms, but also ensures healthy competition.

- To ensure that the civil space sector focuses research and development of technology and services that benefits all humankind. With a global mandate all member nations would work together in ensuring that R\&D conducted on behalf of the consortium is for civilian purposes only and there is no transfer of critical technology, or of items that may be on the export control lists of member nations. The consortium must also have a defined list of all end users and verification and vetting processes that establish the intent and credentials of the end user.

- To share real time information with consortium members and their relevant agencies with regards to potential threats. Given that any serious space-faring country would be willing to recognize the existence of present and short-term security threats in space, a gradual approach could be implemented that would address the immediate and short-term concerns, then creating a spill-over effect leading to a better mutual political understanding and trust [8].

Such a program would take into account various actors, their values and views with regards to space, and would promote global science by identifying future trends and encouraging regional co-operation. 


\section{FRAMEWORK FOR A GSP}

Let us consider the development and implementation of a new international spaceport, which would provide payload launch capability based on a VML system to member nations as the basis for a GSP. Keeping global policy objectives in mind we can define the following key elements of the structural framework for a GSP.

- Agreement Objective: The objective of the agreement would be to establish a long-term international cooperation framework among partner nations, on the basis of genuine partnership for the detailed design, development, operation and utilization of a VML system, for peaceful purposes in accordance with national and international law. The ideology behind this agreement is to enhance the scientific, technological and commercial use of outer space. The VML system and its various elements shall be developed, operated and utilized in accordance with international law, including but not limited to the Outer Space Treaty, the Rescue Agreement, the Liability Convention and the Registration Convention.

- Management: The system should be established on a multilateral basis and the participating nations, acting through their cooperating agencies will participate and discharge responsibilities in management bodies in accordance with any memorandums of understandings and implementing agreements. The management body shall plan and coordinate activities affecting the design and development of the VML system and its safe, efficient and effective operation and utilization.

- Funding: Each partner nation, acting through their cooperating agencies should bear the costs of fulfilling its respective responsibilities as part of this agreement, including sharing on an equitable basis the agreed common system operations costs or activities attributed to the operation of the VML system as a whole.

- Liability: Except where individual partners have come to an agreement, all partner nations shall remain liable in accordance with the Liability Convention. With regards to the provision of launch and return services provided by the VML system, the partner nations may conclude separate MOU's regarding the appointment of any potential joint liabilities.

- Data Exchange: The agreement shall not require a partner nation to transfer any technical data and goods in contravention of its national laws or regulations. National laws and regulations will apply to all transfers made. All transfers will be limited to cooperating agencies of partner nations. If a private stakeholder has developed the data or goods being transferred, the transfer must be approved by the partner state, which shall in turn act as the contracting agent for any such services.

Considering the above framework and policy recommendations of member nations, it is possible to develop a GSP that would ensure sustainable and secure access to space whilst promoting technology transfer and collaboration amongst member nations. It would also help establish a platform to deal with issues of collective interest, develop agreements that oversee operations and promote transparency.

Most importantly, it would distinguish clearly between the four space sectors and define a unilateral munitions list to ensure non-proliferation of critical technology; thereby opening avenues for trusted nations and end users to trade and transfer technology related to civil and commercial space more openly, leading to greater competition within the industry.

\section{CONCLUSION}

Over the last decade we have witnessed a steady rise in the number of nations interested in accessing space, or space based technology and industry. At the moment there are 28 states with sub-orbital launch capability, 9 with orbital launch capability and 47 states that have accessed space either through indigenous programs or via the commercial sector. As the number of nations accessing space increases, the space environment will become more crowded and complex. Since most technology developed with space programs in mind is dual use, the steady rise in the number of space actors raises security concerns. Whilst there are four main treaties that provide the basis for the sustainable, equitable and secure access to space for current and future users of space, there are a number of nations who have still not acceded to these treaties $[13,14,15]$.

The new US national space policy does echo some of the points discussed in this paper. Whilst the US remains committed to many long-standing tenets governing space activities, it emphasizes the need for expanded international cooperation and the commitment of nations to act responsibly in space in order to prevent mishaps, misperceptions and mistrust. The new commercial and civil space guidelines seem to be designed to expand private sector involvement in space activities; this will encourage and actively promote the export of U.S commercially developed and available space goods and services. After considering the amendments made to the U.S space policy, the suggested ideology behind setting up a GSP is to have an independent body working in conjunction with the current UN structure. The GSP would bring together nations and private investors who are keen to develop technology and conduct space based research, whilst ensuring mandatory compliance of all UN treaties with regards to space. The ethos of such a body would be to ensure sustainable and secure access to space whilst promoting technology transfer and collaboration amongst member groups.

A clear distinction between civil, commercial, intelligence and military technology sectors would open up avenues for trusted nations and private companies to trade and transfer technology related to the civil and commercial space sectors more openly, leading to greater competition within the industry. As the GSP would draw funds from member nations and private firms associated with the body, each investor/actor would have a vested interest in ensuring the security and safe passage of technology and products developed by the GSP. This vital interest by all parties would help promote a peaceful yet competitive environment for future space actors. It would 
also make it possible for emerging space faring nations to participate on a global scale and reap the benefits of space without having to initiate the costly process of setting up an indigenous program.

There are many that would argue that a body like the GSP would be difficult to establish, and its mission objectives would be driven by the current major space players. However, it is important to remember that based on the current financial climate, the growing threat of global warming, depletion of natural resources and the loss of a skilled workforce in the west, there will soon come a time when it would not be possible for nations to run a sustainable national space program without crippling their economy. A GSP would ensure the financial burden on member nations is reduced and its structure would help create a knowledge and skills base that all member nations could use. Most importantly it would provide a more sustainable development path for human exploration of space.

\section{REFERENCES}

[1] Kaufman R., Hetzfeld H., Lewis J., "Space, Security and the Economy", Economists for Peace and Security, September 2008

[2] Defense industrial base assessment: U.S. space industry, US Department of Defence and Department of Commerce, Final Report (Dayton, OH, 2007), 14.

[3] Briefing of the working group on the "Health of the US Space Industrial Base and the Impact of Export Controls", CSIS, Washington D.C, February 2008

[4] Defense Industrial Base Assessment: U.S. Space Industry, U.S. Dept. of Commerce, Bureau of Industry and Security. OMB Control Number: 0694-0119
[5] Presidential Commission on the Future of U.S. Aerospace Industry, Final report of the Commission on the Future of the United States Aerospace Industry, December 2002.

[6] Congressional Research Service, U.S Aerospace Manufacturing: Industry Overview and Prospects, December 2009, 7-5700.

[7] U.S. Government, Defense Industrial Base Assessment, 28.

[8] Pasco X, A European Approach to Space Security, Foundation pour la Recherché Strategique, Paris, July 2006.

[9] Smith M.S, U.S Space Programs: Civilian, Military and Commercial, CRS Issue Brief IB92011 for Congress, The Library of Congress

[10] Sharma, T.; Chatwin, C.; Young, R.; Birch, P.; , "Low cost propulsion systems for the developing world," Recent Advances in Space Technologies, 2009. RAST '09. 4th International Conference on, vol., no., pp.215-220, 11-13 June 200

[11] Sharma, T., Chatwin, C., Long, C., Young, R., \& Birch, P. "Alternative Space Vehicle Launch Systems". AIAA Space 2008 Conference Exposition San Diego California, 2008, 2008-7659. AIAA

[12] Sharma, T., Mitra, B. K., Chatwin, C., Young, R., \& Birch, P. "Advanced MagLev Propulsion System and its Economic Impact". 45th AIAAASMESAEASEE Joint Propulsion Conference Exhibit 2009. AIAA

[13] Williamson R.A, Some Thoughts on Space Policy, presentation to Space Roundtable at McGill University, May 2009.

[14] Walker B.B, Space Security: An Overview, presented at full plenary session of the Conference on Disarmament in Geneva, Switzerland, May $28,2009$.

[15] Williamson R.A, Space policy essentials: The need for consistent elements and clear goals, presented at CRECTEALC Space Policy in Latin-America and the Caribbean: Looking to the Future workshop in Mexico City, November 3-5, 2009. 